\title{
Verb Form and Tense in Arabic
}

\author{
Yasir Alotaibi ${ }^{1}$ \\ ${ }^{1}$ Prince Sattam bin Abdulaziz University, Saudi Arabia \\ Correspondence: Dr. Yasir Alotaibi, Prince Sattam bin Abdulaziz University, Saudi Arabia. E-mail: \\ y.alotaibi@psau.edu.sa
}

Received: June 19, $2020 \quad$ Accepted: July 26, $2020 \quad$ Online Published: July 30, 2020

doi:10.5539/ijel.v10n5p284 URL: https://doi.org/10.5539/ijel.v10n5p284

\begin{abstract}
This paper discusses tense in Arabic based on three varieties of the language: Classical Arabic (CA), Modern Standard Arabic (MSA), and the Taif dialect (TD). We argue against previous analyses that suggest that Arabic is a tenseless language, which assume that tense information is derived from the context. We also argue against the suggestion that Arabic is tensed, but that its tense is relative, rather than absolute. We propose here that CA, MSA, and TD have closely related verb forms, and that these are tensed verbs. Tense in Arabic is absolute in a neutral context and verb forms take the perfective and imperfective aspect. Similar to other languages including English, verb forms in Arabic may take reference from the context instead of the present moment. In this case, we argue that this does not mean that tense in Arabic is relative, because this would also imply that tense in many languages, including English, is relative. Further, we argue that the perfective form indicates only the past tense and the imperfective form, only the present; all other interpretations are derived by implicature.
\end{abstract}

keywords: perfective, imperfective, absolute tense, relative tense

\section{Introduction}

This paper discusses tense in Classical Arabic (CA), Modern Standard Arabic (MSA), and the Taif Dialect (TD). There is a debate in the literature on tense in Arabic and some studies (Wright et al., 1955; Fleisch, 1957; Blach ère \& Gaudefroy-Demombynes, 1975) argue that the Arabic language is tenseless, meaning that tense in Arabic does not come from the form of verb. Rather, tense in this view is derived from the context and other lexical items. The verb form in this kind of analysis is analyzed as indicating aspect rather than tense. Other studies (Comrie, 1985; Fassi Fehri, 1993) argue that verb forms in Arabic indicate tense but suggest that verb forms in Arabic indicate relative tense, rather than absolute tense, meaning that the verb form takes a reference point that is different from the present moment. Other studies, especially traditional studies, analyze verb form as indicating tense but do not discuss the type of tense or aspect that is denoted by the perfective and imperfective forms. This paper will examine all these views about tense in Arabic using the three varieties, CA, MSA, and TD.

The data in this paper include CA, MSA, and TD, which is a vernacular Arabic dialect and spoken in Taif city in Saudi Arabia. All three dialects share the same verb forms, the perfective and imperfective. There are some syntactic differences between CA and MSA, and some researchers believe that the tense system of the two varieties are different (see Comrie, 1985); therefore, we add CA to this study. In some aspects where we believe there is a difference between CA and MSA, we will use written material from CA and in other places, we will assume that the CA form is the same as MSA.

There are two verb forms in Arabic, the perfective and imperfective. The three dialects of Arabic use both stems similarly. The perfective form is inflected through suffixation, while the imperfective form takes prefixes. Both forms inflect for person, number, and gender. However, TD is partly different in the number inflection in that neither form inflects for the dual, but only for the singular and plural. The following examples illustrate the perfective and imperfective form in both CA and MSA in (1a) and (1a), and in TD in (1c) and (1d). 
(1) a. kataba-t sucād-u qașīdat-an. CA/MSA (Perfective)

write.PFV-3SGF Suaad-NOM poem-ACC

'Suaad wrote a poem'

b. taktubu $\quad \mathrm{su}^{\mathrm{c}} \overline{\mathrm{a}} \mathrm{d}-\mathrm{u}$ qașīdat-an. CA/MSA (Imperfective)

3SGF-write.IPFV Suaad-NOM poem-ACC

'Suaad writes a poem'

c. nūrah kataba-t qașīdah. TD (Perfective)

Norah.NOM write.PFV-3SGF poem

'Norah wrote a poem'

d. nūrah t-uktub qașīidah. TD (Imperfective)

Norah.NOM 3SGF-write.IPFV poem

'Norah writes a poem'

This paper is organized as follows: section 2 presents a theoretical overview of tense, including the difference between absolute and relative tense and the meaning of past, present, and future tense. This provides background for the discussion of Arabic tense in the following sections. Section 3 reviews the main viewpoints about tense in Arabic and draws attention to some problems therein. It also discusses the view that analyzes the verb form in Arabic as indicating aspect with- out tense, which assumes that tense in Arabic comes from the context. Further, in this section, we review some studies that analyze tense in Arabic as relative, rather than absolute. Section 4 introduces our perspective on tense in the three dialects and shows that verb forms in Arabic indicate absolute tense with the perfective and imperfective aspect.

\section{Overview of Tense}

Generally, there are two types of tense: absolute tense and relative tense. This section discusses them, their differences, and the main absolute tenses as these are relevant to our analysis of tense in Arabic.

Relative tense is different from absolute tense in that the reference point that is used for locating the situation in time is given by the context, whereas this point is the present moment in the absolute tense. Relative tense differs across languages; that is, some languages use relative tense in subordinate clauses and other in main clauses (see Comrie, 1985; Ducrot et al., 1985). Additionally, relative tense is used in non-finite constructions in some languages and in finite constructions in others. For example, in English, some subordinate clauses use relative tense and take their point of reference from the main clause. Also, in this kind of relative tense, clauses are usually non-finite. The following example illustrates relative tense in English. In this example, the subordinate clause, which is a non-finite clause, contains a participle, and the situation in this clause occurred in the past. The time reference in this clause is relative to a point in the main clause, which contains a finite verb with absolute tense.

(2) The patients awaiting the doctor saw him at $5 \mathrm{pm}$.

In contrast, absolute tense relates the time of the event or situation to the time of utterance. In other words, absolute tense is used for tenses that take the present as a deictic center. However, it does not exactly take the present moment as its deictic center, because it is impossible to deal with the present as one point, while there are an infinite number of points that tenses can be related to (see Comrie, 1985). We will use the term absolute to refer to tenses that take any point in the present as the deictic center. These tenses are the basic ones, namely past, present, and future. In the past tense, the situation is located prior to the time of speech or the present moment; in the present, the situation is coincident with the present or time of speech; and in the future, the situation is located after the time of the speech. The following sections will explain these main three tenses in general and discuss some issues related to them.

\subsection{Present Tense}

The present tense is usually described as a point that coincides with the time of the speech. However, as noted, events do not usually occur at a single moment in the present but are described as the present. Comrie (1985) discusses two types of utterance that contain situations that occur exactly at the present moment, which are performative sentences and simultaneous reports. In per-formative sentences, the act that is described by the 
utterance is performed by the utterance itself. For example, when the speaker utters the sentence in (3a) or the sentence in (3b), they constitute the promise in the first example, which is to meet the hearer, and constitute the performance of naming the boy "David" in the second example. With regard to simultaneous reports, situations can coincide with the present moment if the speaker reports ongoing events. For example, if the commentator of a football match utters the example in (3c), his utterance would coincide with the situation of Renaldo shooting the ball.

(3) a. I promise to meet you.

b. I name this boy "David".

c. Renaldo shoots the ball.

The two types of utterance described above are usually rare, and the present tense is used in many languages to describe other types of utterance. The present tense is used to describe many events that last much longer than the present moment, as long as they also include the present moment. In many cases, the present tense is used for processes or states that include the present moment but that began before that point and may continue after it. The following examples illustrate this idea, in which the state of the book's subject being syntax holds both before the present moment and after it. Similarly, the fact that the student is writing the first chapter includes the present moment, but the process began before the present and continues after it. Although the tense is longer than the present, both examples (and other such sentences) are analyzed as denoting the present tense; this is because they include the present moment.

(4) a. The subject of this book is syntax.

b. The student is writing the first chapter of his thesis.

Aspect is an important feature of a sentence that indicates the length of the event in relation to the tense. For example, in the progressive aspect, the situation occupies a long space of time that encompasses the present moment with other moments in the past and the future. The example in (5a) illustrates progressive English, in which the grammar of this sentence provides a progressive aspect that stretches the period of event's occurrence. In this example, Mary is at the middle of the action when the speaker utters this sentence, and it indicates that the action began before the present moment and proceeds after this moment.

Additionally, the habitual aspect with the present tense means that the situation does not occur once, but it habitually occupies some moments that may not include the present moment. In example (5b) below, Joe goes to school every day and this situation may occur in times that differ from the time of speech, meaning that the speaker may utter this sentence at night, while Joe goes to school in the morning. However, Comrie (1985) argues that habitual sentences do not refer to situations that recur at different intervals, but rather to a habit, which is a characteristic that holds true at the present and other moments. In example (5b), the property of Joe that he goes to school holds even if he is not on his way to school at the moment of utterance.

(5) a. Mary is eating launch.

b. Joe goes to the school (every day).

We conclude that progressive and habitual aspects are different from the present tense, andwe should assume that situations that hold for longer periods of time than the present moment are present because the detail of internal tense is an aspectual issue that does not change the fact that the present tense is used.

\subsection{Past Tense}

In the past tense, the situation is located at a point before the present moment. Similar to the present tense, the past tense shows that the situation occurred before the present moment, without giving further internal details about this tense; that is, it does not show whether the situation ex-tended over time or occurred at a single point. Some deductions about the past tense may be made in individual sentences, which should be assumed to be the result of factors other than the tense.

Comrie (1985) analyzes the present perfect as past as long as the situation described by it occurred before the present moment. The following examples are analyzed as past tense and the difference between their event structures should not change the fact that both situations occurred prior to the present point. In example (6a), the meaning is that in a specific time in the past, which is mutually identified by the speaker and the hearer, David was in London and he has left in other occasion in the past. In contrast, example (6b) means that in some occasion in the past, which is necessarily specified by the speaker and the hearer, the proposition be in London held. The two different interpretations are not contributed by the tense of the two sentences. 
(6) a. David was in London.

b. David has been in London.

The past tense locates situations before the present moment, without giving more details on whether the situation continues to the present moment or even the future. Additionally, the situation described can occupy a long stretch of time in the past or habitually recur more than once. The example in (7a) illustrates the past progressive in English. In this example, Sue was writing a letter at a specific time in the past, but the sentence does not indicate whether the situation reaches the present moment. There are some other factors that may add more information to this proposition and change the meaning of the tense. For example, we can add a clause like but she is now sleeping to show that this situation was completed in the past or the influence of the context may lead the hearer to a different interpretation. Thus, all these changes in the meaning of the past tense are not directly related to the past tense. Additionally, the example in (7b) shows the past tense with habitual aspect, in which the recurrence of the situation is understood from the habitual aspect and not from the past tense. Again, other factors in the context or the knowledge of the hearer may affect this tense and convey that the situation lasted longer than the past. We will assume that this is through implicature and does not change the fact that the tense of the form is the past.

(7) a. Sue was writing a letter.

b. Sue used to go to New York every year.

\subsection{Future Tense}

In the future tense, the situation occurs after the present moment; that is, the directionality of events in the future tense is opposite to the past tense. The future tense is also identical to the past tense in occupying the present moment with an implicature. The following example illustrates this point in English, in which the situation be writing holds at the present moment, but this does not mean that the meaning of the future tense includes the present moment; rather, the future tense in this example was extended by some kind of implicature.

(8) Mary will be writing her thesis when you call on her in two minutes.

However, there is a major difference between the past and future tenses. The situation in the past tense is definite and occurred prior to the present moment and thus cannot be changed in the present moment. In contrast, the future is more speculative in that it may be changed by events that are not expected by the speaker. This raises an important question regarding the difference between the future tense and the past: Is it a difference based on mood or tense? In other words, is the difference between the past tense and the future tense the same as the difference between the past and the present tense? If the answer is no, this means that the future should be assumed to be a mood rather than a tense (see Fleischman, 1982; Comrie, 1985).

Languages differ with regard to the future tense, as some may express the future as tense and others as mood. If a language expresses the future by grammatical expressions that are distinct from other tenses, it is analyzed as tense. Additionally, the future should predict some state of affairs that should occur in the future, and it should be different from modal constructions, which refer to possible worlds. The English example in (9a) makes a definite statement about a situation that should hold in a specific time that is subsequent to the present point. In addition, the truth of this statement can be tested in the future by verifying whether the speaker leaves the next day or not. In contrast, Example (9b) makes reference to a possible world where the speaker leaves tomorrow. The truth of this second claim cannot be tested by verifying whether the speaker leaves the next day, because both situations are compatible with this claim. This means that we can assume that in English, there is a future tense that is different from the modal.

(9) a. I will leave tomorrow.

b. I may leave tomorrow.

Comrie (1985) states that most languages in Europe distinguish between past and non-past, in which the non-past includes the present and the future. These languages have no grammatical distinction between the future and the present or the future and non-future tenses. However, these languages have some future constructions that are only used if there is a possibility of misunderstanding. Although Comrie (1985) claims that these languages have no future tense, this does not imply that the future tense does not exist in other languages in which there are grammatical distinctions between future and non-future. For example, Haiman (1980) states that Hua, a Papuan language, has a grammatical form for future time reference, and in this case, the future tense does not have modal uses. Additionally, some languages such as Dyirbal and Burmese use real and unreal constructions to distinguish between future and non-future, in which the future is usually expressed as an unreal situation because real 
constructions are used for situations that took place in the past or are taking place in the present, while unreal ones are used for hypothetical or predictive situations.

Even in English, there is a debate about the future tense. In traditional grammar, English is analyzed as containing a form for future time reference, which comprises the auxiliary will, as shown in example (9a) above, but will in English has other uses, including modal uses that do not denote future time reference. Additionally, the present form in English can be used for future time reference and this happens in scheduled situations, as shown below in example (10). This means that the future time reference in English is not always indicated by will and will is not always used for denoting the future time reference. This fact supports the controversy about the future tense in the English language (see Geoffrey, 1971). However, despite both problems in the future tense in English, Comrie (1985) argues that English contains a future tense, because will is used as a modal in temporal and conditional constructions, which are special constructions that have different forms. Additionally, the present forms are used for future tense in English in scheduled situations, and they are special constructions as well.

(10) The plane departs at six o'clock tomorrow.

\section{Different Viewpoints}

In the case of Arabic, the debate about tense can be summarized in options: the first suggests that Arabic has no grammatical tense and tense is rather derived from the context, including adverbials and words that contain tense in their lexical meaning. The second posits that the tense in Arabic comes from the grammar and in this case, there has been some disagreement on the type of tense in Arabic. The following subsections will explain the two options and argue against them. Section 3.1 explains the perspective that Arabic has no grammatical tense, where some researchers argue that verb forms in Arabic indicate an aspect without tense. Section 3.2 discusses the argument that supports the proposal that Arabic has a grammatical tense, but this is relative rather than absolute.

\subsection{Aspectual Forms}

Perfectivity and imperfectivity are different types of aspects that show a situation in different ways. Perfectivity describes the situation as a single whole and does not discuss the different intervals that build it. In contrast, imperfectivity shows the internal details of the situation. Thus, the perfective forms usually represent completed situations, while imperfective forms denote the progress of the situation. Imperfectivity includes more than one type of aspect and this means that it can be habitual or continuous, which includes non-progressive and progressive (see Comrie, 1976). The following examples illustrate the three types of imperfectivity in English:

(11) a. John goes to school every day.

b. Louise is wearing a new dress.

c. David is playing football.

The present form in English can indicate two aspects: simple present and habitual present, as in example (11a). The continuous in English has a different form as shown in (11b), which illustrates non-progressive, and (11c), which illustrates progressive.

In Arabic, including CA, MSA, and some modern dialects, the perfective form is used for the perfective aspect, in which the situation is shown as a single whole, and the imperfective form for the imperfective aspect, which includes the habitual and continuous aspects. The following examples illustrate the perfective form in (12a) and the imperfective form in (12b) in MSA (identical to CA and TD):

(12) a. zayd-un dahaba ilā al-madrasat-i.

Zayd-NOM go.PFV.3SGM to DEF-school-GEN

'Zayd went to the school'

b. zayd-un yal'abu kurat-a al-qadam-i kull-a

Zayd-NOM play.IPFV.3SGM ball-ACC DEF-foot-GEN every-ACC

yawm-in/ al-?an-a.

dayGEN/ DEF-now-ACC

'Zayd plays football everyday/ is playing football now'

(12b), which contains a dynamic verb that is compatible with the progressive aspect, has two interpretations in neutral contexts. That is, the aspect indicated by the verb may be habitual-meaning that Zayd habitually plays football —or progressive, meaning that the action was in progress at the time of utterance. Therefore, the adverb kull-a yawm-in 'every day', which is compatible with the habitual aspect, or the adverb al-Pan-a 'now', which is compatible with the progressive aspect, can be used. Moreover, the imperfective form can be used to indicate the 
simple present depending on the meaning of the verb, where stative verbs denote the simple present in the imperfective form and dynamic verbs usually denote habitual or continuous present in the imperfective form. Additionally, the continuous aspect, without other aspects, can be indicated in MSA with the imperfective form of the auxiliary preceding the lexical verb in the imperfective form (see Alotaibi, 2017), as shown below:

(13) zayd-un yakūnu yalcabu kurat-a al-qadam-i.

Zayd-NOM be.IPFV.3SGM play.IPFV.3SGM ball-ACC DEF-foot-GEN

'Zayd is playing football'

The fact that the perfective aspect shows the event as a single whole, which is usually compatible with past time reference, and the imperfective aspect shows the internal details of the tense, which is usually compatible with the present time reference, complicates the analysis of perfective and imperfective forms in Arabic. This means that it is not clear whether both forms indicate tense, aspect, or both. Therefore, verb forms in Arabic are analyzed by some researchers as not indicating tense (see Wright et al., 1955; Fleisch, 1957; Blachère \& Gaudefroy-Demombynes, 1975; Al-Aqarbeh, 2015 among others). Additionally, this view is supported by the fact that Arabic verbs in some contexts may take another reference point rather than the present moment (see Cohen, 1924; David, 1989).

When we analyze Arabic verbs as aspectual, we should answer the important question of where tense information comes from. The answer in some analyses is that the context provides tense information in Arabic (see Anys, 1978; Al-Aqarbeh, 2015). Authors who support this view argue that tense in Arabic comes from the context and not from the grammar or the verb forms. They support this with a few examples from CA or MSA, where the context affects the time reference of certain verb forms. Al-Aqarbeh (2015), in her analysis of MSA examples where lexical verbs follow auxiliaries, assumes that the lexical verb indicates tense if it has a tense. In contrast, we argue that the lexical verb that follows an auxiliary is not tensed but only indicates aspect. The example in (14) is similar to some examples used in (Al-Aqarbeh, 2015, p. 1004) to prove that the perfective form in Arabic is used for a different tense, which is the present in this example. This is an incorrect assumption because the lexical verb in this example follows the auxiliary; therefore, we assume that the auxiliary, which is in the imperfective form, indicates tense and the lexical verb indicates aspect, which is the perfect if we assume that it is an aspect.

(14) yakūnu zayd-un kataba al-risālat-a be.IPFV.3SGM Zayd-NOM write.PFV.3SGM DEF-letter-ACC

al-?ān-a.

DEF-now-ACC

'Zayd has written the letter now'

There are several examples of the context affecting tense in all three varieties of Arabic. How- ever, this happens in all languages that are tensed, and we should be able to distinguish between the meaning of tense and the implicature in some contexts. When tense information is considered in discourse, we must not mix the tense information that comes from the grammar with that derived from context. Therefore, the use of verbs in neutral contexts with different adverbials would be the best test of whether a language expresses tense through grammar. This paper argues that CA, MSA, and TD have grammatical tense, encoded in their verb forms.

We agree with the view that verb forms in Arabic indicate perfectivity and imperfectivty but do not conclude that they are not tensed. The analysis of verbs in Arabic as aspectual poses the following problems: First, this assumption cannot explain many examples in Arabic in which verbs indicate time in both absolute and relative tense constructions. It is true that the perfective aspect is compatible with past, where the event is usually shown as a single point, but this is not only in the past tense; that is, the present and future may also be perfective. Similarly, the imperfective aspect may not be in the present tense alone. Therefore, assuming that verbs in Arabic are aspectual verbs cannot explain how they indicate tense. Assuming that tense is contextually derived deepens the problem because in neutral contexts, Arabic verbs indicate tense. The following examples show that the perfective forms are not compatible with present adverbials in neutral contexts, and imperfective forms are not compatible with past adverbials. (15a) and (15b) are from CA and MSA, and (15c) and (15d) illustrate TD: 
(15) a. *dahaba zayd-un ilā al-dār-i al-Pān-a. go.PFV.3SGM Zayd-NOM to DEF-house-GEN DEF-now-ACC $\mathrm{CA} / \mathrm{MSA}$

'*Zayd wen to the house now'

b. *yadhabu zayd-un ?lā al-dār-i Pamsi. go.IPFV.3SGM Zayd-NOM to DEF-house-GEN yesterday CA/MSA

'*Zayd goes to the house yesterday'

$\begin{array}{ll}\text { c. }{ }^{*} \text { rāḥ } & \text { bandar li al-bayt dalhīn. TD } \\ \text { go.PFv.3SGM Bandar to DEF-house now }\end{array}$

'*Bandar went to the house now'

d. *yurūḥ bandar li al-bayt Pams. TD go.IPFV.3SGM Bandar to DEF-house yesterday

'*Bandar goes to the house yesterday'

These examples demonstrate that Arabic has grammatical tense because in a neutral context, sentences indicate their tense without any support from adverbials or context. The fact that verbs in the perfective form are not acceptable with present adverbials means that these forms encode past tense. In the same way, the fact that the imperfective form is not acceptable with past tense demonstrates that this form encodes present tense.

Second, although the perfective form and the imperfective form, which indicate the past and the present time reference, respectively, sometimes indicate other time references, this does not imply that they are not tensed. This is because, in both Arabic and many other languages, other factors such as context may affect the tense interpretation of verb forms.

Third, copular constructions in Arabic indicate that both forms are tensed. Arabic uses the same forms of verbs in copular constructions, in which copulas have no semantic content and do not show any aspectual information. The copula in the perfective form indicates the past tense and the copula in the imperfective form indicates the present tense. The following examples illustrate the two types of copula:
zayd-un kāna fī al-madrasat-i.
Zayd-NOM be.PFV.3SGM at DEF-school-GEN
'Zayd was at the school'
b. zayd-un wakūnu fì al-madrasat-i.
Zayd-NOM be.IPFV.3SGM at DEF-school-GEN
'Zayd is at the school'

Both copular forms in the examples can be used with lexical verbs, and thus we can assume that copulas indicate tense alone and aspect is indicated by lexical verbs. This means that Arabic is similar to other languages, including English, in using a separate category for certain aspects and its copulas should be analyzed similarly. Thus, if we assume that copulas in Arabic indicate tense, verb forms in Arabic can be assumed to be tensed. Having proved that tense is grammatically encoded in all three varieties of Arabic, including CA, MSA, and TD, we should describe this tense and decide its type. The following section reviews the assumption that Arabic has a relative rather than absolute tense and argues against this analysis.

\subsection{Relative Tense}

Some researchers argue that tense in Arabic is relative rather than absolute. That is, the main clause, which is usually finite, shows relative tense. To this end, Comrie (1985) cites CA as an example of a language that uses relative tense. Comrie (1985) argues that the perfective form in CA is used for relative past, while the 
imperfective form is used for relative non-past. He uses the following examples where the context gives a reference point for a relative time reference. The first is an example from the Holy Quran and the second is an old idiom.

$$
\begin{aligned}
& \text { a. "wa attabac } \bar{u} \quad m \bar{a} \text { tatlū al-šayațīn-u }{ }^{c} \text { alā } \\
& \text { and follow.PFV.3PLM what recite.IPFV.3PLM DEF-devil-NOM on } \\
& \text { mulk-i sulaymān-a". } \\
& \text { reign-GEN Sulayman-GEN } \\
& \text { 'and they followed what the devils used to recite during the reign of } \\
& \text { Sulayman' } \\
& \text { b. "Pağ̄îu-ka Pidā ahmarra al-busr-u". } \\
& \text { come.IPFV.1SGM-2SGM when ruddy.PFV.3SGM DEF-date-NOM } \\
& \text { 'I will come to you when the immature date is ruddied }
\end{aligned}
$$

We note that both examples are not in neutral contexts. (17a) is from a story about the prophet Sulayman and stories usually have a different system of tense, which is affected by the context. Comrie (1985) analyzes this example as containing an imperfective verb, tatlu 'recite', which denotes the past time reference because it is relative to a reference point that was understood from the reign of Sulayman which was in a remote past. We argue that the imperfective verb tatlu 'recite' is not in the main clause because it follows the complementizer $m \bar{a}$ ' 'what'. Thus, this example is like the English example in (2), repeated in (18) below, in that the subordinate clause uses a relative reference point and the only difference is that the verb in the Arabic example is finite if we do not assume the opposite, which is a possible assumption. We argue that this kind of example is insufficient to demonstrate that $\mathrm{CA}$ uses relative tenses. Additionally, we can assume that the reference point in this example is in the main clause, indicated by the perfective verb attaba ${ }^{c} \bar{u}$ 'followed'. With regard to example (17b), it is a conditional sentence and is therefore not in a neutral context because conditional sentences have a different tense system in many languages, including Arabic and English.

(18) The patients awaiting the doctor saw him at $5 \mathrm{pm}$.

However, according to Comrie (1985), in neutral contexts, the perfective and imperfective forms in CA take the present moment as a reference point, but he argues that when any reference point occurs in the context, it is taken to be the reference point instead of the present moment. This means that there is a possibility that tense in CA is absolute rather than relative. The argument that is used by Comrie (1985) to support his analysis is that verbs in CA are compatible with adverbials that should not be compatible in absolute tense. That is, the imperfective form in this language can be used with an adverbial that denotes a past time reference and the perfective form can be used with present time adverbial. However, there are no examples supporting this claim in Comrie (1985), and we find that in neutral contexts, the perfective form cannot be used with present adverbials and the imperfective form is the same in that it cannot be used with adverbials indicating past time, though this may still happen in special contexts with certain kinds of implicature. Our claim is supported by the fact that it is uncontroversial that the examples below are ungrammatical in CA. This is because the perfective form is used in neutral contexts with a present adverbial in (19a) and the imperfective verb in (19a) is used in neutral context with a past adverbial.

$$
\begin{aligned}
& \text { a. *qābala zayd-un }{ }^{\mathrm{c}} \text { amr-an al-?ān-a. } \\
& \text { meet.PFV.3SGM Zayd-NOM Amr-ACC DEF-now-ACC } \\
& \text { '*Zayd met Amr now' } \\
& \text { b. *yuqābilu zayd-un camr-an Pamsi. } \\
& \text { meet.IPFV.3SGM Zayd-NOM Amr-ACC yesterday } \\
& \text { '*Zayd is meeting Amr yesterday }
\end{aligned}
$$

However, the English and Arabic examples in (19a) may be acceptable if the meaning is that it is the case now that Zayd met Amr, but this is an implicature from a special context. We can conclude that tense in CA is not relative tense and that in neutral contexts, perfective forms occur with past adverbials and imperfective forms with present adverbials.

Additionally, tense in MSA and TD is the same in that it is not relative. The perfective form and the imperfective 
form in both dialects take the present moment as a reference point in neutral contexts. The examples in (19) are also representative of MSA: There is no difference between CA and MSA in that both have a perfective form that does not accept present adverbials and an imperfective form that does not accept past adverbials. The following examples in (20) show that TD is the same as CA and MSA, meaning that the perfective form in this dialect is not compatible with the present adverbial and the imperfective form is not compatible with the past adverbial, as shown below:

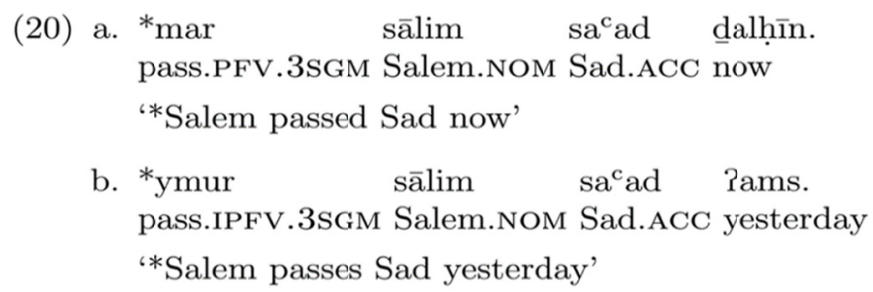

As Comrie (1985) state, the best way to distinguish between real relative tense (where the language takes the deictic center as a reference point if there are no other points of tense) and absolute tense (where the language use other points as a reference point in special contexts) is to use adverbials in neutral contexts. If the verb does not accept an adverbial that makes a different time reference, the tense in the language is absolute tense. This is the case in Arabic. So far, we argue that the three dialects of Arabic have a grammatical category of tense and that this is not relative tense. This means that the three dialects have absolute tense and in the following section, we further describe tense in all three dialects.

\section{A New Perspective}

In this section, we suggest that CA, MSA, and TD have tense and that it is absolute, meaning that tense in Arabic is a grammatical category. The main support for our claim is that specific tenses are indicated in neutral sentences and they are ungrammatical with different adverbials. The examples in (15), repeated in (21), show this fact in the three dialects, in which the perfective form that indicates past tense is ungrammatical with a present adverbial and the imperfective form that indicates present tense is ungrammatical with a past adverbial.

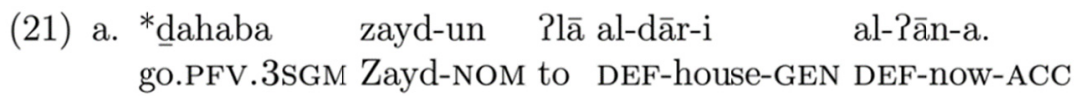
CA/MSA

‘*Zayd went to the house now'

b. *yadhabu zayd-un ?lā al-dār-i Pamsi. go.IPFV.3SGM Zayd-NOM to DEF-house-GEN yesterday CA/MSA

‘*Zayd goes to the house yesterday'

c. *rāḥ bandar li al-bayt dalhīn. TD

go.PFV.3SGM Bandar to DEF-house now

'*Bandar went to the house now'

d. *yurūḥ bandar li al-bayt Pams. TD

go.IPFV.3SGM Bandar to DEF-house yesterday

'*Bandar goes to the house yesterday'

Grammatical tense may be of two types. In the first type, found in many languages, tense is a separate grammatical category, indicated by verbal morphology or by auxiliaries. In the second type, found in a few languages, tense marking is used to indicate tense. For example, in Warlpiri, an Australian language, tense is indicated by tense marking that is part of the auxiliary (see Hale, 1973; Comrie, 1985). Traditional grammarians in Arabic and other languages usually de- scribe tense as a category of verb because the verbal morphology often affects tense in sentences. However, modern studies analyze tense as a category of the sentence because tense is the property of the whole sentence, rather than just the verb (see Lyons, 1977). However, Enc (1982) argues that 
the traditional view of tense is more accurate because noun phrases that function as arguments of verbs are not usually inside the scope of tense.

In this paper, we follow Lexical Functional Grammar (LFG), which is a non-transformational grammatical theory, in assuming that the tense is a property of the clause but is contributed by the verb (see Dalrymple, 2001; Sells, 2007). Therefore, the analysis of a sentence such as (22) requires a lexical entry for the verb, which shows that the tense is contributed by the verb and requires an f-structure, containing the tense information in the clause. The lexical entry is shown in (23) and the f-structure in (24):

(22) Mary saw John.

(23) saw

$$
\begin{array}{cl}
I \quad & (\uparrow \text { PRED })=\text { 'see }<\text { SUBJ, OBJ }> \\
& (\uparrow \text { VFORM })=\text { IPFV } \\
& (\uparrow \text { TENSE })=\text { PAST }
\end{array}
$$

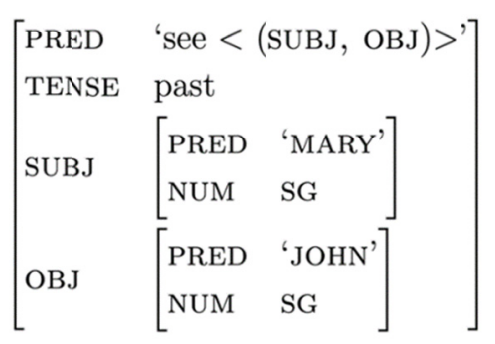

If we assume that the tense is a property of the sentence or verb, verbs play an important role in identifying the tense of sentence. Therefore, in the following subsections, we will focus on verbs and suggest that the perfective and imperfective forms in Arabic are tensed, indicating absolute tense with perfective and imperfective aspect.

\subsection{Tenses in Arabic}

In this section, we will discuss tense in Arabic, which we propose is a grammatical category. We think that the perfective form in Arabic indicates the past tense and this past is perfective, meaning that the event is viewed as a single point without any details. Additionally, the imperfective form in the three dialects indicates the present tense with the imperfective aspect, which includes the habitual and continuous aspects, with the latter including the progressive and nonprogressive. The following subsections will discuss the type of grammatical tense in Arabic.

\subsubsection{Past Tense}

As mentioned above, past tense in Arabic is indicated by the perfective form. We assume that the perfective form in the three dialects indicates the past tense in neutral contexts and also the perfec- tive aspect, meaning that this form shows that the situation occurred before the present moment. The perfective form in some contexts may be used for other tenses in the three dialects, but this is more in CA because we usually find CA in written sources that contain stories, whose conventions usually affect the tense of the verb form used. The following example from the Holy Quran shows that this form is used for the future tense.

$$
\begin{array}{llll}
\text { (25) "Patā } & \text { Pamr-u } & \text { allāh-i, fa-lā tasta }{ }^{c} \text { ğilū-h" CA. } \\
\text { be.PFv.3sGm comand-NOM God-GEN so-NEG } & \text { rush-3sGm }
\end{array}
$$

'God's command came, so do not rush it'

The verb came in (25) is in the perfective form, but the tense is not the past, because the second part of this verse is 'do not rush it'; this means that the command of God (the day of judgement) has not come yet. This means that the tense in this verse is the future, rather than the past and the verb is in the perfective form to indicate that the day of judgement is not far. Thus, we may conclude that the context in this example affects the tense. However, we cannot conclude from this that tense is contextual in CA or that the perfective form indicates the future tense because this is a special meaning derived from a special context. We claim that the perfective form in CA is used to contribute past tense and all other tenses that come from this form are derived through implicature. MSA is close to CA, but in this regard, MSA does not usually use this kind of implicature, because the speakers of MSA, who acquired it in school, usually follow prescriptive grammar rules that restrict the perfective form to the past tense. 
TD is like CA and MSA in that the perfective form is used for the past tense in the neutral con- text, but in some contexts, the perfective form may be used for other tenses. The native speakers of this dialect may use the perfective form for the future tense to indicate that the hearer should assume that the event took place in the past, meaning that it is like CA in the previous example. They are therefore like other languages in this regard. The following examples illustrate the perfective form with future interpretations:
a. hassan nağạ
fì al-ḩtibār. TD
Hassan.NOM pass.PFV.3SGM in DEF-exam

'Hassan passed the exam'

The context: the speaker saw Hassan working hard before the exam.

b. al-bayt gallaq. TD

DEF-house finish.PFV.3SGM

'The house has been finished'

The context: the speaker saw someone's house that was nearly completed.

In both examples, the perfective form is used with future interpretation. In example (26a), Hassan has not taken the exam yet, but the speaker uses the perfective form in this context to indicate that after Hassan's hard work, they are sure that he will pass the exam. In the same way, the house in (26b) has not been completed, but the speaker uses the perfective form to indicate that they assume that it will be completed soon. This usage of the verb form is not unique to Arabic and other languages may have similar contexts; we should assume that the perfective form in TD is mainly used for the past tense and other interpretations are derived through implicature. However, both examples in (26) are not usually grammatical with time adverbials that refer to the future. The following examples are illustrative:
a. *hassan nağah fì al-htibār bukrah. TD
Hassan.NOM pass.PFV.3SGM in DEF-exam tomorrow
'*Hassan passed the exam tomorrow'
b. *al-bayt gallaq $\quad$ ba $^{c} d$ yūmayn. TD
DEF-house finish.PFV.3SGM after two.days
'*The house has been finished after two days'

The tense that is indicated by the perfective form in all the three dialects is the absolute tense, meaning that the present moment is the deictic center here. This is the case when this form is used in a neutral context, but in some contexts, this form may be used to indicate relative tense. For example, when the perfective form occurs in an embedded clause, it takes a reference point from the main clause as a deictic center. The following examples illustrate this point for CA and MSA in (28a) and for TD in (28b):

$$
\begin{aligned}
& \text { a. qāla zayd-un șâliḥ-un dahaba rilā } \\
& \text { say.PFV.3SGM Zayd-NOM Salih-NOM go.PFV.3SGM to } \\
& \text { al-bayt-i. } \quad \text { CA/MSA } \\
& \text { DEF-house-GEN }
\end{aligned}
$$

'Zayd said that Salih went to the house'
b. ${ }^{\mathrm{c} a l} \mathbf{1}$ hassab muhammad nağah
Ali.Nom think.PFV.3SGM Muhammad.NOM succeed.PFV.3SGM in
al-ahtibār. TD
DEF-exam

'Ali thought that Muhammad passed the exam'

In both examples, both the main clause and the embedded clause contain a verb in the perfective form. However, the difference between the perfective verb in the main clause and the one in the embedded clause is that in the main clause the situation denoted by the verb occurred before the present moment. In the embedded clause, it occurred before the situation in the main clause, meaning that the perfective form in the embedded clause takes the event in the main clause as a reference point. 
As stated above, this paper suggests that the perfective form in Arabic indicates the past tense and also the perfective aspect, which represents the situation as a single whole, without showing the internal details of tense. This does not mean that Arabic has no aspect in the past tense. Imperfectivity can be shown in the three dialects by using compound verb phrases, meaning that auxiliaries can precede lexical verbs to achieve the imperfective aspect. In this case, the auxiliary should be in the perfective form because it indicates the past tense and the lexical verb should be in the imperfective form because it indicates aspect. The following examples are ambiguous between two interpretations, namely, habitual and continuous aspect (the three dialects have identical structures in this case). (29) illustrates imperfectivity in CA and MSA, while (30) illustrates it in TD:
(29) a. fāris-un kāna yalcabu fì al-hadīqat-i
Faris-NOM be.PFV.3SGM play.IPFV.3SGM in DEF-garden-GEN
?amsi. CA/MSA
yesterday
'Faris was playing in the garden yesterday'
b. fāris-un kāna yalcabu fī al-ḥadīqat-i
Faris-NOM be.PFV.3SGM play.IPFV.3SGM in DEF-garden-GEN
kull-a yawm-in. CA/MSA
every-ACC day-GEN
'Faris used to play in the garden every day'
(30) a. bassām kān $\quad$ yil $^{c} a b \quad$ fì al-šāric ${ }^{c}$
Bassam.NOM be.PFV.3SGM play.IPFV.3SGM in DEF-street
?ams. TD
yesterday
'Bassam was playing in the street yesterday'
b. bassām kān yil ${ }^{\mathrm{c} a b} \quad$ fī al-šāri ${ }^{\mathrm{c}}$ kul
Bassam.NOM be.PFV.3SGM play.IPFV.3SGM in DEF-street every
yawm. TD
day
'Bassam used to playing in the street every day'

Both (29a) and (30a) indicate the continuous past because the adverb restricts the meaning to the continuous. Similarly, (29b) and (30b) indicate the habitual past due to the adverb. Thus, this construction in the three dialects indicates imperfectivity, which contains the habitual and continuous, because the lexical verb is in the imperfective form and it contributes the imperfective aspect.

Finally, we note that the perfective form is used as a non-finite form in the three dialects when it follows an auxiliary. The following examples illustrate this structure in CA and MSA in (31a) and TD in (31b):

(31) a. zayd-un yakūnu dahaba Pilā al-dār-i.

Zayd-NOM be.IPFV.3SGM go.PFV.3SGM to DEF-house-GEN

CA/MSA

'Zayd has gone to the house'

b. manāl tukūn rāḥat li al-madrasah. MSA

Manal.nOM be.IPFV.3SGF go.PFV.3SGF to DEF-house-GEN

'Manal has gone to the school'

\subsubsection{Present Tense}

In traditional grammar, the imperfective form in CA and MSA is considered to be the present, but traditional grammarians stated that it is sometimes able to indicate future (Hasan, 1998). In addition, in an analysis of MSA, Fassi Fehri (1993) argues that the imperfective form is a non-past form, meaning that it indicates both the present 
and the future. This statement is different from the analysis of this form in traditional grammar because in traditional grammar, it is assumed that the basic tense of this form is the present. In this paper, we posit that the imperfective form indicates the present tense only and that the future is derived through implicature. This analysis is supported by the use of the imperfective form in neutral contexts. When we use the imperfective form in a sentence that does not occur in a special context, it is understood to be in the present tense. The following examples from MSA are illustrative:
b. Pahmad-u yaktubu qașidat-an. MSA
Ahmad-NOM write.IPFV.3SGM poem-ACC

'Ahmad writes a poem'

In the examples above, only a present tense interpretation can be derived; the future tense can be understood only in special contexts. However, when we use future adverbials with sentences that contain imperfective forms, they are grammatical. This means that both examples in (32), when they occur with a future adverbial such as 'tomorrow', are grammatical, as shown below.
(33) a. fāris-un yal ${ }^{\mathrm{c}} \mathrm{abu}$ fī al-ḥadīqat-i ġad-an.
Faris-NOM play.IPFV.3SGM in DEF-garden-GEN tomorrow-ACC
MSA

'Faris will play in the garden tomorrow'

b. Paḥmad-u yaktubu qașidat-an ġad-an. MSA

Ahmad-NOM write.IPFV.3SGM poem-ACC tomorrow-ACC

'Ahmad will write a poem tomorrow'

We maintain that both examples above cannot occur in a neutral context with the future adverb. Both examples should be in a special context, namely, one that uses them as a result of something. Thus, the example in (33a) should occur in a context such as where Faris was sick, then became well and thus will play in the garden tomorrow. Similarly, the example in (33b) should occur in a context, such as one where Ahmad took some courses about writing poems and the result is that he will write a poem tomorrow. We believe that these are special contexts and that the future interpretation of the imperfective form is derived by implicature.

Interestingly, when the imperfective form is stative verbs, similar examples would be odd with future adverbials. The following examples, which contain stative verbs such as know and believe, are unusual in MSA:
(34) a. $\mathrm{su}^{\mathrm{c}} \overline{\mathrm{a}} \mathrm{d}-\mathrm{u} \quad \mathrm{ta}^{\mathrm{c}} \mathrm{rifu}$
al-ğawab-a gad-an.
Suaad-NOM know.IPFV.3SGM DEF-answer-ACC tomorrow-ACC
MSA

'Suaad will know the answer tomorrow'
b. Laylā tuṣaddiqu al-Phbār-a gad-an.
Layla-NOM believe.IPFV.3SGM DEF-news-ACC tomorrow-ACC MSA

\section{'Layla will believe the news tomorrow'}

More support for our claim that the imperfective form in Arabic indicates the present tense comes from the TD dialect. The imperfective form in TD is used only for the present tense. Therefore, the following examples that contain imperfective forms in TD are not grammatical with future adverbials: 


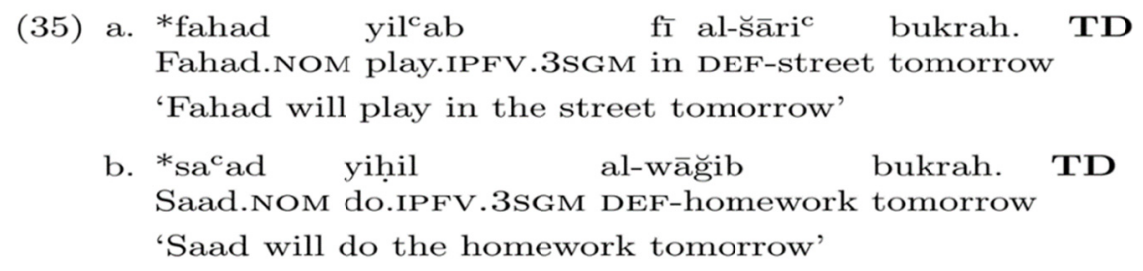

Besides the present tense, the imperfective form in the three dialects indicates the imperfective aspect, which includes habitual and continuous present. This means that examples such as (32), repeated as (36) below, can be used with adverbials like every day or now. Also, the imperfective form in TD indicates the imperfective aspect, as in (37) below:

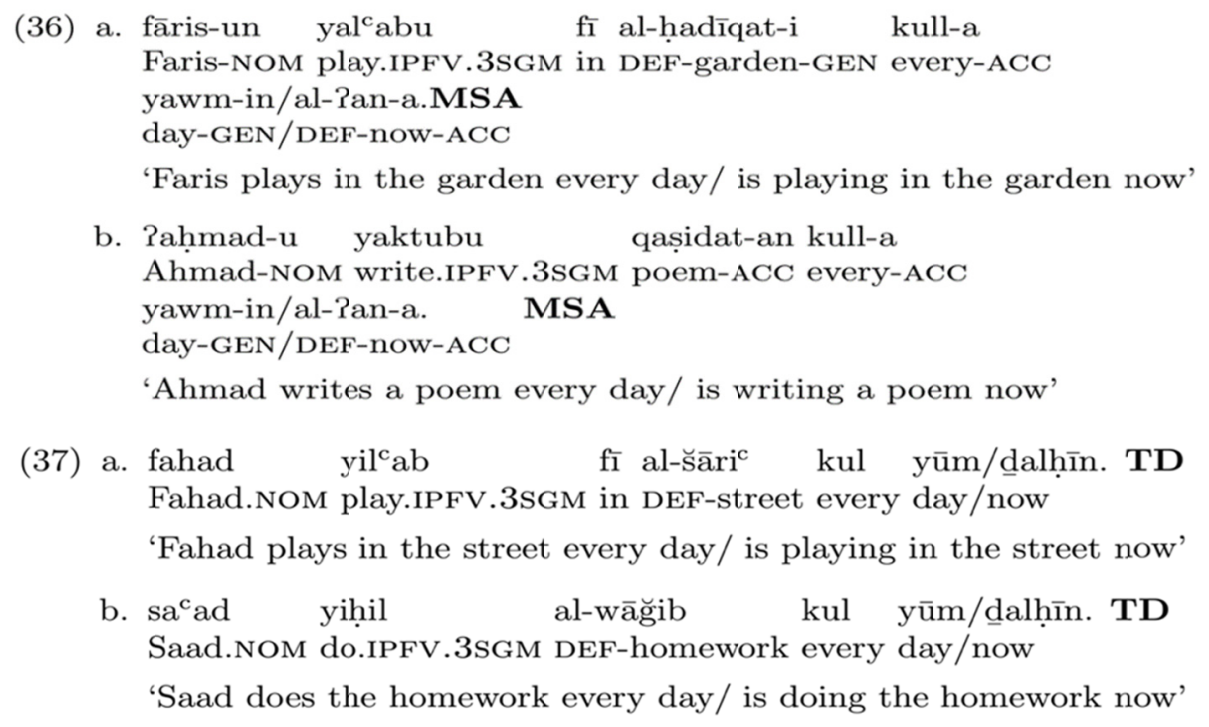

In addition, the imperfective form can be used as a non-finite verb in all three dialects. We assume that the imperfective form can be non-finite in three structures: the first is when the imperfective form is in subjunctive or jussive mood and this is possible in CA and MSA and impossible in TD. The second is when the imperfective follows an auxiliary or a lexical verb that indicates the tense. The third is when future particles precede this form. All the three dialects share the second and third structure. The three structures will be discussed below.

The previous discussion was for the indicative mood of the imperfective form in Arabic. The imperfective form is different from the perfective form in that it can show the subjunctive and jussive mood. In the subjunctive mood, the short vowel at the end of the verb changes from Damma (in the indicative) to Fatha. The imperfective form in the subjunctive mood appears after the following particles: lan, which negates the situation in the future, li, kay, hattaa, which express the purpose, and Pan, which is used as a complementizer to link the subordinate clause and the main clause (see Ryding, 2005). This paper is concerned about the tense of the imperfective form in this mood, which is future, but we do not suggest that the imperfective form in this mood indicates the future. That is, we argue that the imperfective form in this case is a non-finite form and the tense comes from the particle that precedes the verb, which indicates the future. Similarly, the imperfective form is in jussive mood if it follows another group of particles, which are lam, lamm $\bar{a}, l \bar{a}$, and li. lam and lamm $\bar{a}$ are negative particles, while $l \bar{a}$ is the negative imperative particle and $l i$ is the imperative particle. In the jussive mood, the imperfective verb loses the short vowel at the end of it (see Ryding, 2005). Additionally, the imperfective form shows the jussive mood in certain kinds of conditional sentences. This paper will not discuss the imperative meaning in the jussive mood or conditional sentences because these types of sentences are different and need different analyses. The following examples show the subjunctive mood in (38a) and the jussive mood in (38b): 
(38) a. sālim-un lan yadhaba Tilā al-madrasat-i.

Salim-NOM will.not go.IPFV.3SGM to DEF-school-GEN

Subjunctive

'Salim will not go to the school'

b. sālim-un lam yadhab Pilā al-madrasat-i. Jussive

Salim-NOM did.not go.IPFV.3SGM to DEF-school-GEN

'Salim did not go to the school'

In both examples above, we suggest that the imperfective form is non-finite and the future interpretation in (38a) is indicated by the negative particle lan, while the past interpretation in example (38b) comes from the negative particle lam (see Al Sharif \& Sadler, 2009) for more information about negative particles in MSA).

The second structure that contains the non-finite form of the imperfective is when the imperfective form follows an auxiliary or a lexical verb. In the first case, we assume that the auxiliary indicates the tense and the imperfective form, which contains the imperfective aspect, indicates the aspect. As explained above, the imperfectivity includes two aspects: the habitual and continuous and both interpretations can be derived when the imperfective form follows an auxiliary in the perfective form, while the continuous is only understood when the imperfective follows an auxiliary in the imperfective form. All the three dialects are the same in using an infinitive imperfective form after auxiliaries. The following examples are illustrative:

(39) a. sālim-un kāna yal cabu al-ḥadiqat-i. Salim-NOM be.PFV.3SGM play.IPFV.3SGM in DEF-garden-GEN

\section{CA/MSA}

'Salim was playing in the garden'

b. fāțimah qa ${ }^{\mathrm{c}}$ adat til ${ }^{\mathrm{c}} \mathrm{ab}$ fì al-bayt.

Fatemah.NOM be.PFV.3SGF play.IPFV.3SGF at DEF-house.GEN

TD

'Fatemah was playing at the house'

In both examples above, the time reference is the past and we assume that the auxiliaries in both examples indicate the past and the lexical verbs, which are in the imperfective form, contribute the aspectual information, which is continuous (i.e., imperfective) in both examples.

In addition, the imperfective form may follow a lexical verb and function as a depictive, as analyzed in traditional grammars. When the imperfective form follows a lexical verb in this structure, it does not indicate any tense. The following examples show this structure in all threedialects:

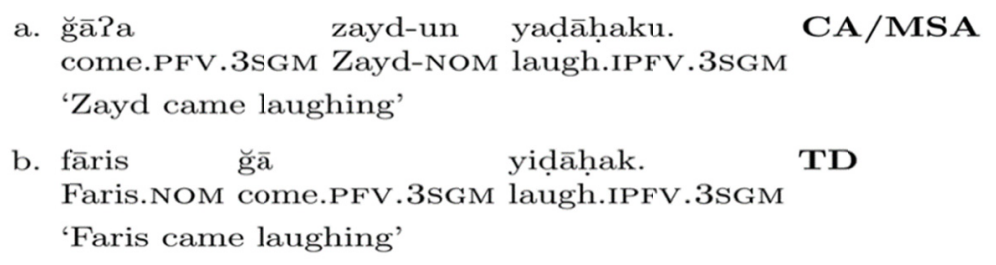

In both examples above, the imperfective form is non-finite and is different from certain structures that contain the imperfective form in an embedded clause, indicating a relative tense to the verb in the main clause. The following examples illustrate the imperfective form indicating a relative tense: 


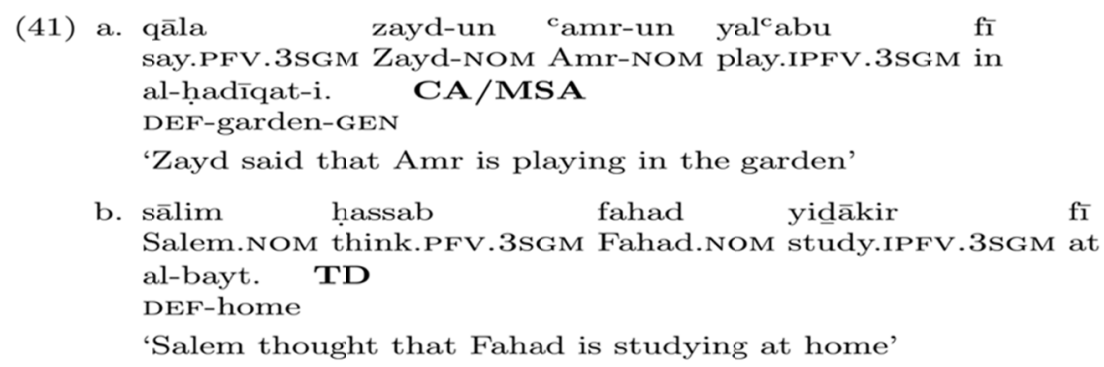

In both examples in (41), the time reference of the imperfective form in the embedded clause is related to the time reference of the perfective form in the main clause. This means that $A m r$ in (41a) was playing in the past when Zayd said that. Similarly, Fahad in (41b) was studying in the past when Salem thought that.

The third structure that contains a non-finite imperfective form is when the imperfective follows a future particle in all the three dialects. The future particles in CA and MSA are the prefix $s a$ and the particle $s a w f a$, while TD uses the prefix $b i$ preceding the imperfective form. The following examples are illustrative:
a. Paḥmad-u sa-yusāfiru gad-an. CA/MSA
Ahmad-NOM will-travel.IPFV.3SGM tomorrow-ACC
'Ahmad will travel tomorrow'
b. Paḥmad-u sawfa yusāfiru ba ${ }^{c} d-a \quad$ sahr-in. Ahmad-NOM will travel.IPFV.3SGM after-ACC month-GEN CA/MSA

\author{
'Ahmad will travel after one month' \\ c. Paḥmad bi-ysāfir bukrah. TD \\ Ahmad.NOM will-travel.IPFv.3SGM tomorrow \\ 'Ahmad will travel tomorrow'
}

There is a difference in the degree of remoteness between $s a$, which is shown in example (42a), and sawfa, which is shown in example (42b), namely, the first is for the near future while the latter is for the far future (see Alansari, n.d.). In contrast, TD uses one particle for all kind of future.

We thus find that all the three dialects have a future tense, meaning that it is a tense rather than a mood. As mentioned above, languages differ in how they encode the future tense, in that some languages use mood instead of tense. We suggest that the future in all the examples in (42) has a separate grammar that is distinct from other tenses in these dialects. Additionally, in these examples, the future tenses make predictions about events that should occur in the future in the real world. In all the examples in (42), Ahmad will travel in a specific time in the future and the truth value of this statement can be tested at that time.

\title{
5. Conclusion
}

This paper has presented arguments against two analyses for tense in Arabic. In the first, verb forms are analyzed as tenseless verbs, indicating aspect only. In the second analysis, verb forms are analyzed as indicating a relative tense, rather than absolute. We propose an alternative analysis where the perfective and imperfective form in CA, MSA, and TD are shown to indicate absolute tense with perfective aspect in the first and imperfective aspect in the second. We argue that this is the case in neutral context. Further, this paper assumes that the tense in the three dialects may come from the context in some special cases and may be the relative tense in other special contexts. In this regard, Arabic is not different from other languages. Importantly, the paper shows that the system of tense in some varieties of Arabic dialects is the same.

\section{Acknowledgement}

This project is supported by the Deanship of Scientific Research at Prince Sattam Bin Abdulaziz University and the number of the research project is $2020 / 02 / 16438$.

\section{References}

Al-Aqarbeh, R. N. (2015). Temporal interpretation in standard and Jordanian Arabic $=\nvdash Ł \succeq € € €$. Dirasat: Human and Social Sciences, 48(3111), 1-28.

Al Sharif, A., \& Sadler, L. (2009). Negation in modern standard arabic: A lfg approach. In E. Alansari (Ed.), 
muqni allabib. dar alfikr.

Alotaibi, Y. H. (2017, January). The analysis of auxiliaries in modern standard Arabic. Journal of Faculty of Languages and Translation, 12(2).

Anys, E. (1978). min asrar alluqah. alanjlu almasriah.

Blachère, R., \& Gaudefroy-Demombynes, M. (1975). Grammaire de l'arabe classique: mor-phologie et syntaxe. Maisonneuve \& Larose.

Cohen, M. (1924). Le systeme verbal semitique et l'expression du temps (Volume 5). E. Leroux.

Comrie, B. (1976). Aspect. Cambridge Textbooks in Linguistics. Cambridge, UK: Cambridge University Press.

Comrie, B. (1985). Tense. Cambridge University Press. https://doi.org/10.1017/CBO9781139165815

Dalrymple, M. (2001). Lexical functional grammar (Volume 42). Academic Press New York.

David, C. (1989). L'aspect verbal. Paris, PUF. https://doi.org/10.1163/9781849500104

Ducrot, O., Tzvetan, T., \& Osten, D. (1985). Tense and aspect systems.

Enc, M. (1982). Tense without scope: An analysis of nouns as indexicals.

Fassi Fehri, A. (1993). Issues in the structure of Arabic clauses and words. Dordrecht: Kluwer. https://doi.org/10.1007/978-94-017-1986-5

Fleisch, H. (1957). Etudes sur le verbe arabe: Extrait des Melanges Louis Massignon. Institut Francais de Damas.

Fleischman, S. (1982). The future in thought and language. diachronic evidence from romance. Cambridge Studies in Linguistics London, 36.

Geoffrey, L. et al. (1971). Meaning and the English verb. London: Longman.

Haiman, J. (1980). Hua, a Papuan language of the eastern highlands of New Guinea (Volume 5). John Benjamins Publishing. https://doi.org/10.1075/slcs.5

Hale, K. L. (1973). Person marking in Walbiri.

Hasan, A. (1998). alnahw alwafi. dar alfikr.

Lyons, J. (1977). Semantics (volume 1). Cambridge: Cambridge University Press. https://doi.org/10.1017/CBO9780511620614

Ryding, K. (2005). A reference grammar of modern standard Arabic. Cambridge: Cambridge University Press. https://doi.org/10.1017/CBO9780511486975

Sells, P. (2007). Finiteness in non-transformational syntactic frameworks (pp. 59-88). Finiteness: Theoretical and empirical foundations.

Wright, W., de Goeje, M., \& Smith, W. (1955). A grammar of the Arabic language. University Press.

\section{Copyrights}

Copyright for this article is retained by the author, with first publication rights granted to the journal.

This is an open-access article distributed under the terms and conditions of the Creative Commons Attribution license (http://creativecommons.org/licenses/by/4.0/). 